\title{
Nucleostemin mRNA is expressed in both normal and malignant renal tissues
}

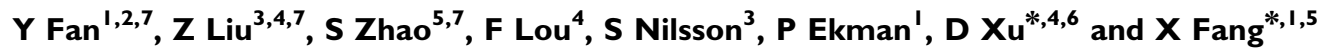 \\ 'Department of Surgery, Division of Urology, Division of Hematology, Karolinska University Hospital, SE-I 7 I 76 Stockholm, Sweden; ${ }^{2}$ Department of \\ Urology, Qilu Hospital, Shandoing University, Jinan, 2500 I2, PR China; ${ }^{3}$ Department of Oncology-Pathology, Division of Hematology, Karolinska University \\ Hospital, SE-I 7176 Stockholm, Sweden; ${ }^{4}$ Aging and Health Center, Nursing School, Shandong University, Jinan, 2500 I 2, PR China; ${ }^{5}$ Institute of Urology, \\ Shandong University, Jinan, 2500 I 2, PR China; ${ }^{6}$ Department of Medicine, Division of Hematology, Karolinska University Hospital, SE-1 7176 Stockholm, \\ Sweden
}

Nucleostemin (NS), a p53-binding protein, has been shown essential for stem and cancer cell proliferation and implicated in oncogenesis. To explore potential contributions of NS to the development of clear cell renal cell carcinomas (ccRCCs), we determined NS expression in $\mathrm{ccRCC}$ cell lines, and in paired normal and malignant renal tissues from 31 patients with ccRCC. Nucleostemin mRNA and/or protein expression was observed in all four cell lines and 27 of 31 (87\%) tumour specimens. Surprisingly, 16 of 31 (52\%) adjacent normal renal samples also expressed NS mRNA and its levels in four of them were comparable with those in paired tumour tissues. Three of the patients had detectable NS mRNA in their normal renal tissues whereas lacked its expression in the matched tumours. Compared to the oncogene c-MYC expression in these same samples, NS expression showed a much less specificity for ccRCC. We further demonstrated that NS mRNA expression was closely associated with cellular proliferation in normal fibroblasts or T lymphocytes and renal cell carcinoma cell lines. Collectively, NS expression widely occurs in normal and malignant renal tissues, and is likely a proliferation marker rather than a unique regulator of cell proliferation and survival in stem and cancer cells.

British Journal of Cancer (2006) 94, 1658- |662. doi:I0.1038/sj.bjc.6603|45 www.bjcancer.com

Published online 2 May 2006

(c) 2006 Cancer Research UK

Keywords: nucleostemin; RCC; renal tissues; c-MYC

Renal cell carcinoma (RCC), the most common malignant tumour of the adult kidney in both developed and developing countries, accounts for $2-3 \%$ of all human malignancies with close to 100000 yearly deaths worldwide (Whang and Godley, 2003; Lam et al, 2005; Patel et al, 2006). As a pathologically and genetically heterogeneous disease, RCC falls into at least four subtypes, including clear-cell, a predominant type (about $80 \%$ ) and others (papillary, chromophobe, and collecting duct carcinomas). In clear cell renal cell carcinoma (ccRCC), inactivation of the von HippelLindau disease tumour suppressor (VHL gene) by different mechanisms is widespread and believed to be an early or a first event during the oncogenic process (Foster et al, 1994; Gnarra et al, 1994; Brauch et al, 2000; Linehan et al, 2004; Maher, 2004). However, molecular mechanisms underlying the full development of ccRCC are largely unknown. Clinically, approximately $30 \%$ of patients with ccRCC present with widely disseminated diseases, and even higher percentages of patients treated with complete

*Correspondence: Dr D Xu, Haematology Laboratory, Center for Molecular Medicine (CMM), L8:03, Karolinska University Hospital, SE- I7I 76 Stockholm, Sweden; E-mail: Dawei.Xu@cmm.ki.se or X Fang, Institute of Urology, Shandong University, Jinan, 250033, PR China; E-mail: xiaoleifang@sdu.edu.cn

7 These authors contributed equally to this work.

Received 15 June 2005; revised 3 April 2006; accepted 5 April 2006; published online 2 May 2006 surgical resection undergo metastatic progression within a short period (Glaspy, 2002; Pantuck et al, 2003; Whang and Godley, 2003; Lam et al, 2005; Patel et al, 2006). Moreover, recurrent ccRCC responds poorly to the current biotherapy and chemotherapy (Donskov et al, 2006; Patel et al, 2006). Although a number of molecular and clinical parameters have been shown as prognostic markers for ccRCC (Campbell et al, 2003; Elmore et al, 2003; Kallio et al, 2003; Schips et al, 2003; Thomas et al, 2003; Kallio et al, 2004; Zigeuner et al, 2004; Dudderidge et al, 2005), the clinical outcome of patients with ccRCC shows a broad variation. Therefore, better defining the pathogenesis of ccRCC, looking for reliable early diagnostic markers, and exploring novel intervention targets for ccRCC are urgently demanding tasks.

One of the most important hallmarks for cancers is their deregulated cellular proliferation. The aberrant activation of the oncogene c-MYC, observed in many different types of human cancers, has been implicated as a driving force for abnormal cell growth (Nasi et al, 2001; Hermeking, 2003). More recently, a p53binding protein, named nucleostemin (NS) abundantly expressed in stem and cancer cells but silenced in differentiated cells, has been shown to be essential for stem and cancer cell proliferation and survival (Tsai and McKay, 2002). It is currently unknown whether this newly identified molecule is involved in ccRCC pathogenesis. In the present study, we investigated NS mRNA expression in both normal and malignant renal tissues, and examined potential relationships between its expression and 
clinico-pathological characteristics in ccRCC. Additionally, because NS shares certain similarities with the oncogene c-MYC in terms of expression profile and functional properties (Nasi et al, 2001; Tsai and McKay, 2002), we further compared the NS expression profile with the $c-M Y C$ activation in ccRCC.

\section{PATIENTS AND METHODS}

\section{Cell lines and cell culture}

Four ccRCC cell lines, A498, KRC/Y, CAKI-2, and TK10, were maintained at $37^{\circ} \mathrm{C}$ in Dulbecco's modified Eagle's medium (Life Technologies, Paisley, UK) supplemented with $10 \%$ fetal calf serum (FCS), $2 \mathrm{mM} \mathrm{L-glutamine,} 100 \mathrm{U} \mathrm{ml}^{-1}$ penicillin and streptomycin, under $5 \% \mathrm{CO}_{2} / 95 \%$ air. Cells at logarithmically growing phases were harvested for reverse transcription-polymerase chain reaction (RT - PCR) analyses of NS and c-MYC mRNA expression. To determine the relationship between NS expression and cellular proliferation, the cells were incubated in $0.2 \%$ FCS-containing medium for $72 \mathrm{~h}$ to induce quiescence and then re-fed with $20 \%$ FCS for $24 \mathrm{~h}$. Normal T lymphocytes were isolated from the buffycoaded blood derived from normal individuals and treated with $15 \mu \mathrm{g} / \mathrm{ml}$ ConA to stimulate their proliferation. Normal dermal fibroblasts were kindly provided by Dr Z. Yan (Karolinska Institute, Sweden).

\section{Patients and tissue specimens}

The ccRCC tumour samples and their adjacent normal renal tissues were obtained from 31 patients with primary ccRCC. The study was approved by the local ethics committee, and all the patients consented to the use of their renal tissues for the present investigation. The patients were treated with radical nephrectomy at Qilu Hospital, Shandong University, between 2002 and 2003. After surgery, the tumour specimens and adjacent normal renal tissues were stored at $-80^{\circ} \mathrm{C}$ until use. For each ccRCC, tumour size (diameter), Robson stage, and regional and distant metastases at nephrectomy were evaluated by both pathologists and urologists. Patient and disease information is listed in Table 1.

\section{RNA extraction, reverse transcription, and polymerase chain reaction}

Total cellular RNA was extracted using the ULTRASPEC ${ }^{\mathrm{TM}}$-II RNA kit (Biotecx Lab., Houston, TX, USA). cDNA was synthesised using random primers (N6) (Pharmacia, Uppsala, Sweden) and M-MLV reverse transcriptase. The polymerase chain reaction (PCR) primer sequences specific for NS mRNA (Accession number: AY825265) were: 5'-GAA ACA GAG GCT TGA AGA ACT AA (forward) and 5 '-GGA GGC TTC GAT CAC CTT TTT A (reverse). Polymerase chain reaction was performed with the use of 32 amplification cycles $\left(95^{\circ} \mathrm{C}\right.$ for $15^{\prime \prime}, 64^{\circ} \mathrm{C}$ for $30^{\prime \prime}$, and $72^{\circ} \mathrm{C}$ for $\left.30^{\prime \prime}\right)$ and the PCR product was $223 \mathrm{bp}$ in length. The RT-PCR for the oncogene c-MYC mRNA (Accession number: HSMYC1) was performed as described (Garrett et al, 2002), and the primer sequences were: forward: TAC CCT CTC AAC GAC AGC AGC TCG CCC AAG TCC T and reverse: TCT TGA CAT TCT CCT CGG TGT CCG AGG ACC T, which led to the amplification of a $479 \mathrm{bp}$ long DNA fragment. A total of $30 \mathrm{PCR}$ cycles at $95^{\circ} \mathrm{C}$ for $15^{\prime \prime}, 60^{\circ} \mathrm{C}$ for $45^{\prime \prime}$, and $72^{\circ} \mathrm{C}$ for $60^{\prime \prime}$ was carried out. $\beta$-Actin expression was used as an internal control and amplified with its specific primers using 25 cycles (Fan et al, 2005). Polymerase chain reaction products were resolved in $2 \%$ agarose gels, stained with ethidium bromide, and visualized in ultraviolet light. The PCR conditions were optimised to make sure a linear amplification of each target, and PCR results for NS and c-MYC were recorded as negative $(-)$, moderate positive $(+)$, and strongly positive $(++)$ based on their signal intensities and $\beta$-actin reference.
Table I Patients' characteristics, nucleostemin, and c-MYC mRNA expression in ccRCCs and adjacent normal renal tissues

\begin{tabular}{|c|c|c|c|c|c|c|c|}
\hline \multicolumn{4}{|c|}{ Clinical/pathological information } & \multicolumn{2}{|c|}{ Tumours } & \multicolumn{2}{|c|}{ Normal tissues } \\
\hline Patient & $\begin{array}{c}\text { Agel } \\
\text { gender }\end{array}$ & $\begin{array}{l}\text { Sizes } \\
(\mathrm{cm})\end{array}$ & Stages & $\mathbf{N S}^{\mathbf{a}}$ & c-MYCa & NS & c-MYC \\
\hline I & $56 / M$ & 5.0 & I & + & ++ & - & + \\
\hline 2 & $54 / F$ & 4.5 & I & ++ & + & + & + \\
\hline 3 & $56 / M$ & 5.5 & I & ++ & ++ & - & - \\
\hline 4 & $52 / M$ & 8.0 & I & - & + & + & + \\
\hline 5 & $47 / F$ & 7.5 & I & + & ++ & - & - \\
\hline 6 & $54 / F$ & 6.0 & I & - & $\mathrm{ND}^{2}$ & + & ND \\
\hline 7 & $54 / F$ & 10.0 & I & ++ & + & - & - \\
\hline 8 & $64 / M$ & 8.0 & I & - & + & - & - \\
\hline 9 & $68 / F$ & 4.5 & I & ++ & ++ & - & - \\
\hline 10 & $57 / M$ & 6.5 & I & + & ++ & - & - \\
\hline | | & $76 / M$ & 5.0 & I & + & + & + & - \\
\hline 12 & $44 / M$ & 2.5 & I & ++ & ++ & - & - \\
\hline 13 & $62 / M$ & 3.0 & I & + & + & - & - \\
\hline 14 & $48 / F$ & 3.0 & I & ++ & ++ & + & - \\
\hline 15 & $74 / M$ & 3.0 & I & ++ & ++ & + & + \\
\hline 16 & $57 / F$ & 4.0 & I & ++ & ++ & + & - \\
\hline 17 & $51 / M$ & 3.0 & I & + & + & + & + \\
\hline 18 & $68 / M$ & 6.0 & I & ++ & + & - & - \\
\hline 19 & $79 / F$ & 3.0 & I & ++ & ++ & + & - \\
\hline 20 & $36 / M$ & 6.5 & I & ++ & + & - & - \\
\hline 21 & $48 / F$ & 8.0 & I & ++ & ++ & + & - \\
\hline 22 & $43 / M$ & 4.5 & I & + & ++ & + & - \\
\hline 23 & $63 / M$ & 4.5 & I & + & + & - & - \\
\hline 24 & $39 / F$ & 5.0 & II & + & + & + & + \\
\hline 25 & $48 / M$ & 8.0 & $\|$ & ++ & ++ & + & - \\
\hline 26 & $68 / M$ & 10.5 & $\|^{\mathrm{Mb}}$ & ++ & ND & - & ND \\
\hline 27 & $69 / M$ & 8.0 & $\|^{M}$ & ++ & ++ & - & - \\
\hline 28 & $64 / M$ & 8.0 & \|\|$^{\mathrm{M}}$ & ++ & ++ & + & + \\
\hline 29 & $54 / M$ & 12.5 & $I^{M}$ & - & + & + & - \\
\hline 30 & $28 / F$ & 15.5 & $\mathrm{IV}^{\mathrm{M}}$ & ++ & ++ & + & + \\
\hline 31 & $64 / M$ & 7.0 & $\mathrm{IV}^{\mathrm{M}}$ & + & + & - & - \\
\hline
\end{tabular}

ccRCCcs = clear cell renal cell carcinomas; ND = not done; NS= nucleostemin; $\mathrm{PCR}=$ polymerase chain reaction. ${ }^{\text {a }} \mathrm{PCR}$ results for $\mathrm{NS}$ and $\mathrm{c}-\mathrm{MYC}$ were recorded as negative $(-)$, moderate positive $(+)$, and strongly positive $(++)$ based on their signal intensities. ${ }^{\mathrm{D}} \mathrm{M}$ : With metastasis.

\section{Western blot}

Western blot was performed as described (Xu et al, 2000). Briefly, total proteins were extracted with sodium dodecyl sulphate lysis buffer, and $50 \mu \mathrm{g}$ of the proteins were resolved by sodium dodecyl sulphate-polyacrylamide gel electrophoresis and transferred to an intracellulos membrane. The membranes were probed with the specific primary antibody against NS (Cat\# 14-86-42-80; eBioscience, San Diego, CA, USA) followed by secondary antirabbit horseradish peroxidase-conjugated IgG and developed with the enhanced chemiluminescent method (ECL, Amersham, UK).

\section{Immunohistochemistry}

Immunohistochemical staining was performed as described earlier (Zhang et al, 2000). Following deparaffinization, antigen unmasking, and inactivation of endogenous peroxidase, the primary antibody against NS (eBioscience, San Diego, CA, USA) was 1:10 diluted, added onto slides, and incubated at $4{ }^{\circ} \mathrm{C}$ overnight. An antibody binding was visualised by using the secondary antibodies conjugated with horseradish peroxidase and an AEC kit according to the manufacturers' protocols (Dako Corporation, Denmark). The slides were finally counterstained with haematoxylin. Coverslips were mounted onto glass slides and examined with a light microscope equipped with a CCD camera (Nikon, Eclipse E800, Japan). 
1660

\section{RESULTS}

\section{NS mRNA and protein expression in ccRCC cell lines}

We first examined NS mRNA and protein in cultured ccRCC cell lines. For this purpose, A498, KRC/Y, CAKI-2, and TK10 cells were used and all the four cell lines contained NS mRNA, as determined by using RT - PCR (Figure 1A, left panel). The result demonstrated

A

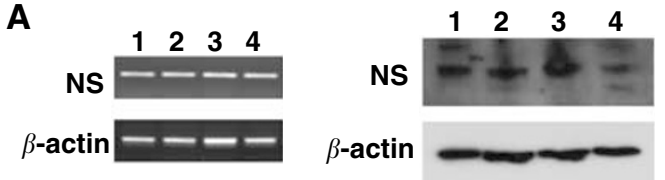

B

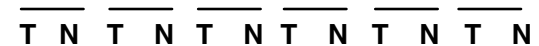

NS
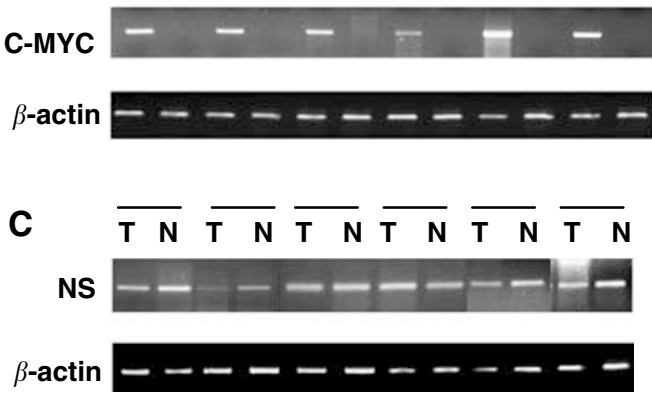

D

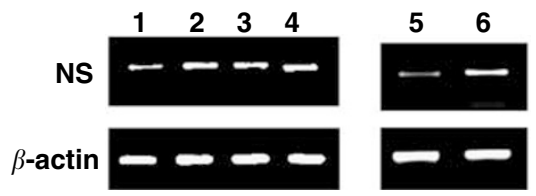

Figure I Nucleostemin expression in normal and malignant renal tissues and other types of normal human cells. (A) Nucleostemin mRNA (left panel) and protein (right panel) expression in ccRCC cell lines. Lane I: A498 cells; 2: TK I0; 3: KRY/C, and 4: Caki2. (B) and (C) NS and c-MYC mRNA expression in ccRCC samples and their adjacent normal renal tissues. (D) Nucleostemin mRNA expression in normal human fibroblasts, T lymphocytes, and A498 cells and relationship with cell proliferation statuses. Lanes I and 2: normal fibroblasts at senescence and at early passage, respectively. Lanes 3 and 4: normal resting and activated $T$ lymphocytes, respectively. Lane 5: ccRCC A498 cells with serum-starvation for $72 \mathrm{~h}$. Lane 6: A498 cells undergoing $72 \mathrm{~h}$ serum-starvation were re-fed with $20 \%$ serum for $24 \mathrm{~h}$. that ccRCC tumour-derived cells, like other types of human cell lines reported previously, exhibited a transcriptional activation of the NS gene. Consistent with its mRNA expression, NS protein was readily detectable in all these cell lines with the use of an immunoblotting assay (Figure 1A, right panel).

\section{NS mRNA and protein expression in primary ccRCC specimens}

We next carried out NS mRNA analyses in primary ccRCC samples. A total of 31 tumours obtained from 31 patients with ccRCC were examined and NS mRNA detected in 27 of them $(86 \%$, Table 1, Figure $1 \mathrm{~B}$ and $\mathrm{C}$ ). Compared to the cell lines, those primary tumours had largely similar levels of NS mRNA. Moreover, we further performed immunohistochemical analyses on 10 available tumour specimens to examine NS protein expression. Nine of 10 examined patient tumours exhibited a positive staining for NS in more than $20 \%$ cells and in all the positive specimens, NS was observed in both cytoplasmic and nuclear compartments of tumour cells (Figure 2). This distribution profile of NS was very similar to that found in gastric cancers (Yang et al, 2005). The staining intensity of the NS protein was in general consistent with its mRNA expression in the examined tumour specimens.

We then compared NS expression with clinico-pathological parameters, and found no significant associations between the presence of NS mRNA and patients' age, gender, tumour sizes, disease stages, and metastases.

\section{Detectable NS mRNA expression in more than half of adjacent normal renal tissues}

We then wanted to ask whether transcriptional activation of the NS gene also occurred in normal renal cells. The adjacent normal renal samples from these 31 patients were analysed for NS mRNA expression, and unexpectedly, 16 of them (51\%) expressed detectable NS mRNA (Table 1 and Figure 1C). Of these NSexpressing normal samples, the levels of NS mRNA in nine cases were lower than in their paired tumours and in four patients were comparable with their tumour counterparts. Intriguingly, it was observed in three patients that NS mRNA was only present in their normal renal tissues whereas absent in their tumour specimens (Table 1, patients 4, 6, and 29). Taken together, NS mRNA is expressed in normal human renal tissues with a high frequency.

\section{A close relationship between NS expression and cell proliferation in normal human cells and ccRCC cells}

To determine whether other kinds of normal cells express NS, we analysed NS mRNA in normal human T lymphocytes and dermal fibroblasts. As shown in Figure 1D, NS mRNA was readily
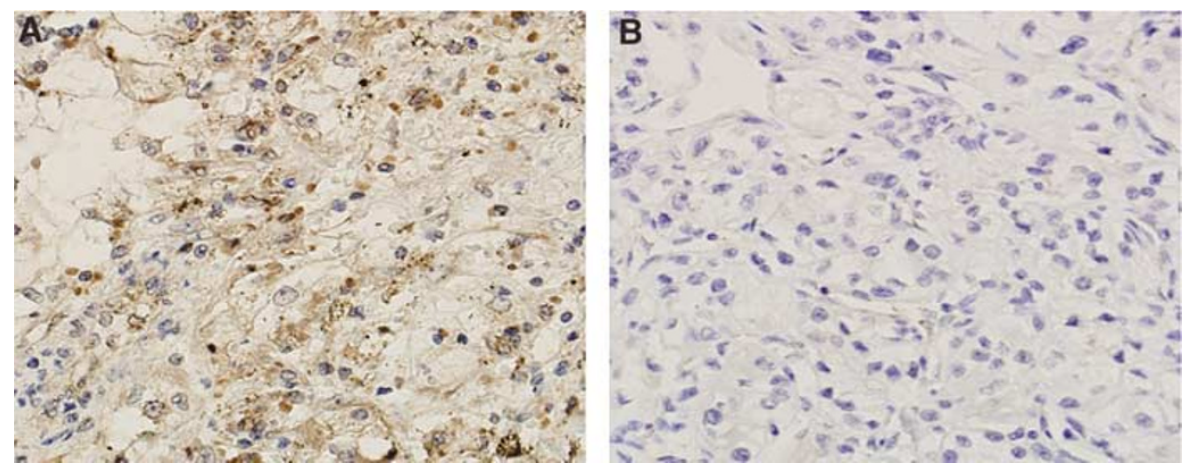

Figure 2 Immunohistochemical analyses for NS protein expression in tumour specimens derived from patients with ccRCC. Representative positive (A) and negative $(\mathbf{B})$ stainings are shown. 
detectable in both cell types. We further observed that $\mathrm{T}$ lymphocytes activated by ConA expressed higher NS mRNA than did the resting cells, and that senescent fibroblasts had lower abundances of NS mRNA compared to the cells at early passages.

The above result suggests that NS may be a universal proliferation marker rather than a specific regulator for proliferation of undifferentiated stem and cancer cells. To test this hypothesis, we examined the kinetic changes in ccRCC cell lines at quiescent and actively proliferating phases. We first induced quiescence of A498 cells by maintaining them in $0.2 \%$ of FCS for $72 \mathrm{~h}$ and then stimulated their proliferation by transferring them into $20 \%$ FCS-containing medium. The RT - PCR analyses clearly demonstrated significant downregulation of NS expression in G0 cells, but increased NS mRNA abundance following re-entry into cell cycle (Figure 1D).

\section{The oncogene c-MYC expression in normal and cancerous renal tissues}

We finally analysed c-MYC mRNA expression in this same set of patients' specimens. c-MYC mRNA was found in all 29 examined tumour samples. Twenty-one of 29 adjacent normal renal tissues lacked detectable c-MYC mRNA (Table 1 and Figure 1B). Although eight of those normal samples expressed c-MYC mRNA, the expression level was much lower compared to that in their paired tumour tissues. We found no associations between NS and c-MYC expression in both normal and malignant renal tissues, indicating independent transcriptional regulation of two genes.

\section{DISCUSSION}

Tsai and McKay (2002) have recently identified NS, a novel p53-binding protein that is abundantly present in stem cells and stem cell-enriched tissues. Interestingly, both NS mRNA and protein are absent in adult differentiated cells/tissues, although highly expressed in different human cancer cell lines (Tsai and McKay, 2002). Depletion of NS inhibits cell proliferation in both stem and cancer cells, indicating its functional importance in maintaining cell cycle progression of those cells. Prompted by these interesting findings, we set out to investigate whether NS has roles in RCC development, and if so, whether this molecule can serve as a diagnostic marker or therapeutic target for RCC.

In the present study, we observed NS expression in all four examined ccRCC cell lines and in 27 of 31 primary tumours, suggestive of its widespread in primary ccRCC, consistent with that seen in human cancer cell lines. Surprisingly, more than the half of adjacent normal renal specimens also contained NS mRNA, and the expression level in four of them was comparable with their paired tumour tissues. In three patients, NS mRNA was present in their normal renal tissues but absent in their tumours. Moreover, we have similarly observed that both normal and cancerous prostate tissues expressed rather high levels of NS mRNA (X Fang, $\mathrm{P}$ Ekman, and $\mathrm{D} \mathrm{Xu}$, unpublished data). These unexpected findings challenge the early concept of NS being a specific player for stem and cancer cell proliferation. However, one may argue that (1) tumour cell contamination in adjacent normal renal tissues may contribute to detectable NS mRNA expression, as seen here. However, these same specimens have previously been used for analyses of telomerase activity and full-length of telomerase reverse transcriptase mRNA expression, highly specific markers for transformed cells, and both markers were exclusively absent in all the studied adjacent normal tissues (Fan et al, 2005), which suggests the lack of contaminated tumour cells in the normal samples used in this study. (2) The stem cells present in kidneys and prostates may be a source of NS mRNA. However, stem cells in somatic tissues kidneys and prostates are in a rather low number, and are unlikely a major contributor to the observed NS expression in these organs. Our further identification of NS mRNA expression in purified $\mathrm{T}$ lymphocytes and fibroblasts strongly indicate that many types of differentiated human cells, if not all, do express NS transcripts. Taken together, we conclude that NS expression is not a unique feature for ccRCC and prostate cancers, neither for stem cells.

According to our preliminary data, NS expression is proliferation-regulated and induced in actively cycling cells such as presenescent human fibroblasts and activated T lymphocytes. On the other hand, in vitro cultured RCC cells undergo downregulation of NS expression in response to serum starvation. Regardless being stem cells, cancer cells, or normal differentiated cells, they may all acquire NS expression when in actively proliferating status. Therefore, NS is more like a proliferation marker rather than a molecule only involved in the cell cycle control of stem and cancer cells. This proposal provides a reasonable explanation for what have been seen in normal renal and prostate tissues: detectable NS transcript in them is virtually expressed by proliferative epithelial or other types of cells; and NS-expressing stem cells are negligible owing to their very low numbers.

In normal stem cells and U2OS cells, NS protein was exclusively localised in nucleus (Tsai and McKay, 2002). However, the primary ccRCC tumour cells examined here exhibited both cytoplasmic and nuclear localisations of NS, although a nuclear compartment with a stronger signal. This distribution pattern of NS has recently been observed in gastric cancers, too (Yang et al, 2005). It is currently unclear how and why such a cytoplasmic localization occurs, which calls for further investigations.

The oncogene c-MYC plays a key role in regulating cell proliferation and its aberrant activation contributes to the pathogenesis of many human malignancies including RCC (Nasi et al, 2001). From expression and functional points of view, c-MYC and NS share certain similarities: (1) both are abundantly present in stem cells and downregulated in differentiated cells and (2) their expression levels should be within a limited window, and both depletion and overexpression lead to cell growth arrest and/or apoptosis. Thus, we determined NS and c-MYC mRNA expression in parallels. c-MYC mRNA was expressed in all 29 tumours examined, whereas lower or comparable levels of c-MYC expression was only observed in 8/29 normal renal samples. Compared to NS, c-MYC is a more specific marker for ccRCC.

The study presented herein demonstrates that NS is widely expressed in both ccRCC and adjacent normal renal tissues, in sharp contrast with the recent report that NS is present in stem and cancer cells whereas absent in differentiated adult tissues (Tsai and McKay, 2002). Although the levels of NS expression are higher in most tumours than their paired normal renal tissues, there was no significant correlation between NS expression and patients' clinico-pathological characteristics. Compared to the c-MYC oncogene, NS expression shows less specificity for ccRCC, and is unlikely to serve as a diagnostic marker and therapeutic target for RCC. Our findings call for re-evaluation of the NS expression profile in various normal human tissues, and more rigorous delineation of its oncogenic role in human cell transformation.

\section{ACKNOWLEDGEMENTS}

We thank Ms L Garberg for immunohistochemical staining, Drs M Wang for analyses of immunohistochemistry results and Z Yan for human dermal fibroblasts. The study was supported with the grants from the Swedish Cancer Society, Cancer Society in Stockholm, Swedish Research Council, Swedish Society of Medicine, Karolinska Institute, and Urological Research Foundation, Karolinska Hospital, Nursing School of Shandong University. DX is a research fellow of the Swedish Research Council. 


\section{REFERENCES}

Brauch H, Weirich G, Brieger J, Glavac D, Rodl H, Eichinger M, Feurer M, Weidt E, Puranakanitstha C, Neuhaus C, Pomer S, Brenner W, Schirmacher P, Storkel S, Rotter M, Masera A, Gugeler N, Decker HJ (2000) VHL alterations in human clear cell renal cell carcinoma: association with advanced tumor stage and a novel hot spot mutation. Cancer Res 60: $1942-1948$

Campbell L, Gumbleton M, Griffiths DF (2003) Caveolin-1 overexpression predicts poor disease-free survival of patients with clinically confined renal cell carcinoma. Br J Cancer 89: 1909 - 1913

Donskov F, Hokland M, Marcussen N, Torp Madsen HH, von der Maase H (2006) Monocytes and neutrophils as 'bad guys' for the outcome of interleukin-2 with and without histamine in metastatic renal cell carcinoma - results from a randomised phase II trial. Br J Cancer 94: 218-226

Dudderidge TJ, Stoeber K, Loddo M, Atkinson G, Fanshawe T, Griffiths DF, Williams GH (2005) Mcm2, Geminin, and KI67 define proliferative state and are prognostic markers in renal cell carcinoma. Clin Cancer Res 11: $2510-2517$

Elmore JM, Kadesky KT, Koeneman KS, Sagalowsky AI (2003) Reassessment of the 1997 TNM classification system for renal cell carcinoma. Cancer 98: $2329-2334$

Fan Y, Liu Z, Fang X, Ge Z, Jia Y, Sun P, Lou F, Björkholm M, Gruber A, Ekman P, Xu D (2005) Differential expression of the full length hTERT mRNA and telomerase activity between normal and malignant renal tissues. Clin Cancer Res 11: 4331-4337

Foster K, Prowse A, van den Berg A, Fleming S, Hulsbeek MM, Crossey PA, Richards FM, Cairns P, Affara NA, Ferguson-Smith MA, Buys CH, Maher ER (1994) Somatic mutations of the von Hippel-Lindau disease tumour suppressor gene in non-familial clear cell renal carcinoma. $\mathrm{Hum} \mathrm{Mol}$ Genet 3: 2169-2173

Garrett SH, Phillips V, Somji S, Sens MA, Dutta R, Park S, Kim D, Sens DA (2002) Transient induction of metallothionein isoform 3 (MT-3), c-fos, c-jun and c-myc in human proximal tubule cells exposed to cadmium. Toxicol Lett 126: 69-80

Glaspy JA (2002) Therapeutic options in the management of renal cell carcinoma. Semin Oncol 29: 41-46

Gnarra JR, Tory K, Weng Y, Schmidt L, Wei MH, Li H, Latif F, Liu S, Chen F, Duh FM, Lubensky I, Duan DR, Florence C, Pozzatti R, Walther MM, Bander NH, Grossman HB, Brauch H, Pomer S, Brooks JD, Isaacs WB Lerman MI, Zbar B, Linehan WM (1994) Mutations of the VHL tumour suppressor gene in renal carcinoma. Nat Genet 7: 85-90

Hermeking $\mathrm{H}$ (2003) The MYC oncogene as a cancer drug target. Curr Cancer Drug Targets 3: $163-175$

Kallio JP, Hirvikoski P, Helin H, Kellokumpu-Lehtinen P, Luukkaala T, Tammela TL, Martikainen PM (2003) Membranous location of EGFR immunostaining is associated with good prognosis in renal cell carcinoma. Br J Cancer 89: $1266-1269$
Kallio JP, Hirvikoski P, Helin H, Luukkaala T, Tammela TL, KellokumpuLehtinen P, Martikainen PM (2004) Renal Cell Carcinoma Mib-1, Bax and Bcl-2 Expression and Prognosis. J Urol 172: 2158-2161

Lam JS, Shvarts O, Leppert JT, Figlin RA, Belldegrun AS (2005) Renal cell carcinoma 2005: new frontiers in staging, prognostication and targeted molecular therapy. J Urol 173: 1853-1862

Linehan WM, Vasselli J, Srinivasan R, Walther MM, Merino M, Choyke P, Vocke C, Schmidt L, Isaacs JS, Glenn G, Toro J, Zbar B, Bottaro D, Neckers L (2004) Genetic basis of cancer of the kidney: disease-specific approaches to therapy. Clin Cancer Res 10: 6282S-6289S

Maher ER (2004) Von Hippel-Lindau disease. Curr Mol Med 4: 833-842

Nasi S, Ciarapica R, Jucker R, Rosati J, Soucek L (2001) Making decisions through Myc. FEBS Lett 490: $153-162$

Pantuck AJ, Zeng G, Belldegrun AS, Figlin RA (2003) Pathobiology, prognosis, and targeted therapy for renal cell carcinoma: exploiting the hypoxia-induced pathway. Clin Cancer Res 9: $4641-4652$

Patel PH, Chaganti RS, Motzer RJ (2006) Targeted therapy for metastatic renal cell carcinoma. Br J Cancer 94: 614-619

Schips L, Lipsky K, Zigeuner R, Salfellner M, Winkler S, Langner C, Rehak P, Pummer K, Hubmer G (2003) Impact of tumor-associated symptoms on the prognosis of patients with renal cell carcinoma: a single-center experience of 683 patients. Urology 62: 1024-1028

Thomas DH, Verghese A, Kynaston HG, Griffiths DF (2003) Analysis of the prognostic implications of different tumour margin types in renal cell carcinoma. Histopathology 43: $374-380$

Tsai RY, McKay RD (2002) A nucleolar mechanism controlling cell proliferation in stem cells and cancer cells. Genes Dev 16: 2991 - 3003

Whang YE, Godley PA (2003) Renal cell carcinoma. Curr Opin Oncol 15: $213-216$

Xu D, Wang Q, Gruber A, Bjorkholm M, Chen Z, Zaid A, Selivanova G, Peterson C, Wiman KG, Pisa P (2000) Downregulation of telomerase reverse transcriptase mRNA expression by wild type p53 in human tumor cells. Oncogene 19: 5123-5133

Yang H, Zhang J, Wu J, Shou C (2005) Preparation and characterization of monoclonal antibodies against nucleostemin, a protein that controls cell proliferation in stem cells and cancer cells. Hybridoma (Larchmt) 24: $36-41$

Zhang A, Zheng C, Lindvall C, Hou M, Ekedahl J, Lewensohn R, Yan Z, Yang X, Henriksson M, Blennow E, Nordenskjold M, Zetterberg A, Bjorkholm M, Gruber A, Xu D (2000) Frequent amplification of the telomerase reverse transcriptase gene in human tumors. Cancer Res 60: $6230-6235$

Zigeuner R, Ratschek M, Rehak P, Schips L, Langner C (2004) Value of p53 as a prognostic marker in histologic subtypes of renal cell carcinoma: a systematic analysis of primary and metastatic tumor tissue. Urology 63: $651-655$ 